\title{
Apontamentos para uma Filosofia da Comunicașão
}

\author{
Notes towards a Philosophy of Communication
}

\author{
Regina Rossetti \\ Possui Doutorado e Pós-doutorado em Filosofia pela Universidade de São Paulo, \\ Mestrado e Graduação em Filosofia pela Pontifícia Universidade Católica de São \\ Paulo. Atualmente é docente do Programa de Pós-Graduação em Comunicação da \\ Universidade Municipal de São Caetano do Sul - USCS. Tem experiência na área de \\ Comunicação com ênfase em Epistemologia, Filosofia e Teorias da Comunicação. \\ Atua na investigação interdisciplinar entre comunicação e filosofia contemporânea, \\ pesquisando os seguintes temas: comunicação e inovação, esfera pública, \\ comunicação de interesse público. É editora da revista Comunicação \& Inovação.
}

\section{RESUMO}

Este artigo trata da relação entre Comunicação e Filosofia ao apontar alguns momentos em que a comunicação foi objeto de reflexão filosófica. A Comunicação instituída como área do conhecimento é algo muito recente e pertence à história do século XX, embora a comunicação como fenômeno seja tão antiga quanto à própria humanidade. Já a comunicação como tema discutido pelo pensamento ocidental remonta aos filósofos gregos, como Platão e Aristóteles, e contemporaneamente a pensadores como Nietzsche, Bergson, Foucault e Hannh Arendt, dentre outros mais óbvios. O objetivo deste artigo é apontar dentro da História da Filosofia ocidental alguns momentos em que diversos filósofos trataram do tema da comunicação, e assim sugerir um aporte para uma reflexão interdisciplinar sobre temas ligados a comunicação.

Palavras-chave: Filosofia da comunicação; cinema; música; tempo; discurso; visibilidade.

\section{ABSTRACT}

This article deals with the relationship between Communication and Philosophy to point out a few times when communication is philosophical reflection object. The Communication established as a field of knowledge is something very new and belongs to the history of the twentieth century, although the communication as a phenomenon is as old as humanity itself . Already the communication theme discussed by Western thought goes back to the Greek philosophers like Plato and Aristotle, and simultaneously the philosophers such as Nietzsche, Bergson, Foucault and Hannh Arendt and others more obvious. The purpose of this article is to point in the History of Western Philosophy few times when many philosophers dealt with the theme of communication, and so suggest a contribution to an interdisciplinary reflection on communication issues.

Keywords: communication and innovation; philosophy of communication. 


\section{Introdução}

Filosofia e comunicação dialogam desde os primórdios do pensamento ocidental. Enquanto uma capacidade humana, a comunicação foi objeto de reflexão filosófica desde os gregos que, se não trataram dela diretamente, trataram de temas afins. Platão, ao conceber seu mundo das ideias, parte de um conceito de imagem que ignora o movimento e, assim, de certa forma, se aproxima do mecanismo cinematográfico. Aristóteles afirma que o homem é um animal que fala e que possui um discurso racional ao definir a natureza humana. Ao tratar do espírito dionisíaco e do apolíneo nas artes, Nietzsche, fala da música e da canção. Bergson enfrenta a dura tarefa de comunicar o tempo e propõe a metáfora como possibilidade de comunicação mais adequada a fugaz natureza temporal. Foucault trata diretamente do discurso contextualizado em epistemes específicas e Hannah Arendt fala do discurso que dá visibilidade a ação humana.

Este artigo, ao tratar da relação entre Comunicação e Filosofia, busca apontar alguns momentos em que a comunicação é objeto de reflexão filosófica. Ao indicar dentro da História da Filosofia ocidental algumas ocasiões em que diversos filósofos trataram do tema da comunicação, pretende ser mais um aporte para uma reflexão interdisciplinar sobre temas da comunicação.

\section{Platão e o cinema}

Platão não tratou diretamente da comunicação, mas ao conceber seu Mundo das Ideias, partiu de um conceito de imagem que se aproxima muito do mecanismo cinematográfico inventado mais de dois mil anos depois. A Teoria das Ideias do filósofo ateniense Platão (427ac - 347ac) ignora o movimento inerente à própria realidade. Isso porque ideia para Platão (1983) é eidos, isto é, forma imutável acima do devir, essência perfeita destituída de qualquer movimento. O platonismo utilizou metodicamente da atividade de isolamento e reestruturação do movimento, em função de sua concepção extratemporal do ser inteligível. Seguindo a análise de E. Moutosopoulos (1980, p. 44), vemos que em Platão, primeiro, a realidade é confinada em certos estados isolada no intemporal estático, como unidades acabadas e sujeitas a uma contemplação filosófica pela inteligência; segundo, as unidades acabadas e isoladas, as essências, não estão submetidas a nenhum devir, e acabam por adquirir uma permanência inegável, passando a ser consideradas de forma absoluta.

O cinema, por sua vez, utiliza um mecanismo que reconstitui o 
movimento da imagem a partir de fotografias, ou seja, de instantâneos tirados previamente, cuja sequencia é projetada em uma tela, obtendo-se assim, a aparência de movimento. As fotografias em si mesmas são imóveis e permaneceriam assim eternamente se não fosse o aparelho cinematográfico que lhes acrescenta artificialmente o movimento.

Platão utiliza o mesmo mecanismo para conceber o movimento a partir das ideias imutáveis. A razão da utilização deste mecanismo está na própria atitude filosófica platônica que é dualista: fundada numa parte sobre o ser e noutra parte sobre o devir. Este dualismo dá passagem a uma metafísica estática que põe o princípio da realidade (a Ideia) no ser imutável; o que resulta num princípio exterior e isolado do movimento. Quando se passa por fora do devir, a consequência é uma visão cinematográfica das coisas e dos seres, visão que também pode ser encontrada na Filosofia das Ideias de Platão, quando constatamos a imutabilidade e não imanência de seu princípio. "O que significa que se chega à filosofia das Ideias quando se aplica o mecanismo cinematográfico da inteligência à análise do real” (MOUTOSOPOULOS, 1980, p. 44).

A partir desta constatação do método cinematográfico, o termo eídos, além de significar forma ou ideia, também pode ser traduzido por visão ou momento. Neste sentido, eídos pode ser entendido como um momento do devir ou uma visão estável da instabilidade das coisas: a qualidade é um momento do devir; a forma é um momento da evolução; a essência é a forma média antecipada do movimento, ou seja, o desenho inspirador do ato acabado.

A Filosofia das Ideias reduz as coisas às ideias, porque abstrai do devir seus momentos principais, como se tirasse fotografias dos momentos essenciais do fluxo das coisas, aplicando o mecanismo cinematográfico da inteligência à análise do real. Quando se raciocina por meio deste mecanismo, fazendo sobressair artificialmente instantes privilegiados do decorrer contínuo e indivisível do devir universal, a representação do real daí decorrente é exatamente aquela que se encontra no Platonismo. Segundo Bergson (1971, p. 307), "As grandes linhas da doutrina que evolui desde Platão até Plotino, passando por Aristóteles [...] desenham a visão que uma inteligência sistemática terá do devir universal quando olhar para ele através de instantâneos".

A ontologia platônica, fundada na teoria das ideias, concebe o ser num campo extratemporal, extraduração, e embora reconheça que os seres correspondam a dados sensíveis numa certa temporalidade do devir, insiste que 
em suas essências inteligíveis eles são isolados do devir (MOUTSOPOULOS, 1980 , p.48). Isto porque o platonismo tem uma visão idealizada do mundo, e sua teoria das ideias pode ser qualificada como o resultado de se conceber o devir a partir de imagens imóveis.

Para o Platonismo, o devir não é mais do que uma aparência que a razão rejeita, como sendo contrária aos princípios, longe do qual buscará o fundamento permanente do mundo inteligível. Portanto, a Teoria das Ideias de Platão, ao conceber as ideias como entidades autônomas, imutáveis e isoladas do devir, elevando-as ao estatuto de essência da realidade, acaba por idealizar um princípio exterior e imutável para a realidade movente. Processo esse resultante da aplicação do mecanismo cinematográfico da inteligência e da percepção, que parte do princípio, ilusório, de que o movimento é feito de imobilidades, segundo Bergson (1971, p. 300). A inteligência é conhecimento exterior, possível somente porque se instala fora do movimento. Porém, quando percebidos do exterior, como o faz a inteligência, cada parada virtual é vista como uma imobilidade real, a partir da qual se quer ver surgir o movimento, como se o movimento fosse, agora, feito de imobilidades.

\section{Aristóteles e a fala}

Na polis grega, o homem se revela ao mundo no discurso e na ação. Este fato esclarece a forte relação entre o social e o comunicacional: na fala e no ato, o homem tem visibilidade social no mundo. Quando fala e quando age, o homem é capaz de comunicar a si próprio, e não apenas comunicar alguma coisa, porque na fala ele revela o seu próprio ser. Ação e discurso são definidores da natureza humana e a tornam específica no quadro da natureza em geral.

A dimensão social da comunicação pode encontrar sua primeira indicação teórica em Aristóteles (384-322 ac.). Ao definir o homem como animal racional, isto é, dotado de logos (fala/pensamento), Aristóteles propunha como definidora da natureza humana sua capacidade comunicacional, embora tenha sido formulada de maneira implícita. E, ao fundar sua vida política e social no logos, condicionava a vida social a sua capacidade humana de falar socialmente e, portanto, de comunicar-se. No contexto social e político da polis, exercitar a política implicava em desenvolver os instrumentos humanos de comunicação.

Na Política, Aristóteles nos diz que a fala é o que nos distingue dos animais: 
Assim, o homem é um animal cívico, mais social do que as abelhas e os outros animais que vivem juntos. A natureza, que nada faz em vão, concedeu apenas a ele o dom da palavra, que não devemos confundir com os sons da voz. Estes são apenas a expressão de sensações agradáveis ou desagradáveis, de que os outros animais são, como nós, capazes. A natureza deu-lhes um órgão limitado a este único efeito; nós, porém, temos a mais, senão o conhecimento desenvolvido, pelo menos o sentimento obscuro do bem e do mal, do útil e do nocivo, do justo e do injusto, objetos para a manifestação dos quais nos foi dado o órgão da fala. Este comércio da palavra é o laço de toda sociedade doméstica e civil (ARISTÓTELES, 1998, p. 5)

Para Aristóteles, o homem é um zoon politikón (animal político ou animal cívico), isto é, um ser ético, político e social. É importante observar que Aristóteles, ao definir o homem como um animal político, estava também o definindo como um animal social. A distinção entre sociedade e estado é algo que somente modernamente se fez. O homem político deve ser entendido, no contexto da polis como organização política e social indistintamente, como animal político/social.

Essencialmente destinado à vida em comum na polis somente nela o homem se realiza como ser racional portador de um discurso. O homem é também um zoon logikón (animal racional), isto é, um ser dotado de logos, termo que significa ao mesmo tempo discurso e razão: fala/racional, palavra/ pensamento. Ele é um zoon politikón por ser um zoon logikón, ou seja, porque fala e pensa o homem é capaz de viver em sociedade politicamente organizada. Consequentemente, para os gregos a vida ética e a vida política e social seriam artes de viver segundo a razão que se manifesta na fala.

O gênero ao qual o ser humano pertence é o gênero animal. Como os outros animais ele se move autonomamente. Mas o que o distingue dos outros animais é que ele é um zoon logikón, isto é, um ser que possui um discurso racional. A racionalidade unida ao discurso é a diferença humana específica em relação ao outros animais. Se entendermos que a diferença já é, em si, um tipo de inovação, essa diferença específica é a novidade que o homem traz ao mundo da physis, isto é, ao mundo da natureza. A capacidade de comunicar-se de forma racional no convívio social com outros é o que distingue o homem dos outros animais. Assim, a comunicação social do pensamento é uma novidade no mundo natural. 


\section{Nietzsche e a música}

Para o filósofo alemão Nietzsche $(1844$ - 1900) a estética não é um divertido acessório, algo secundário e sem importância, mas um problema que deve ser levado a sério porque diz respeito a própria "seriedade da existência" isto porque "a arte é a tarefa suprema e a atividade propriamente metafísica da vida". Com seu estilo de filosofar dando marteladas, chama a atenção daqueles que não compreendem a importância da reflexão sobre as questões estéticas e, inadvertidamente, consideram a arte somente diversão: "é possível, porém, que justamente para eles resulte de algum modo escandaloso ver um problema estético tomado tão a sério, caso não estejam em condições de reconhecer na arte mais do que um divertido acessório, do que um tintinar de guizos que se pode muito bem dispensar ante a seriedade da existência" (NIETZSCHE ,1992, p. 26).

Refletindo sobre a arte em $A$ origem da tragédia no espirito da música, Nietzsche propõe dois modelos primordiais de experiência estética, o apolíneo e o dionisíaco. Estes dois modelos foram descobertos e praticados pelos gregos antigos, mas podem servir para compreendemos qualquer forma atual de arte. Nietzsche buscou inspiração nos deuses do panteão grego, Apolo, o deus do sol, e Dionísio, o deus do vinho. Apolo é o deus da clareza, da harmonia e da ordem manifestas nas artes plásticas. "Apolo representa o ideal estético clássico de equilíbrio, serenidade de expressões, harmonia de proporções, de perfeição formal e, sobretudo, de uma individualidade que contempla um espetáculo impassivelmente” (CunHA, 1992, p.257). Dionísio é o deus da exuberância, da desordem e da música. "Neste, o artista tem acesso à experiência simbólica por uma perda da sua individualidade, de modo semelhante ao que ocorre na embriaguez." CunHA (1992. p.259). Não se trata de modelos excludentes, pois há uma coexistência, embora nada pacífica, entre o impulso apolíneo e o impulso dionisíaco que mutuamente se desafiam e se estimulam para dar origem a novas criações, "entre a arte do figurador plástico, a apolínea, e a arte nãofigurada da música, a de Dionísio: ambos os impulsos, tão diverso, caminham lado a lado, na maioria das vezes em discórdia aberta, incitando-se mutuamente a produções sempre novas" (Nietzsche, 1992, p.27).

Embora exista uma música apolínea, a música é por excelência a arte dionisíaca. A música no modelo da arte apolínea, possui uma batida ondulante de ritmo regular e previsível, como são os sons insinuados da cítara. A música de Apolo busca manter distante, aquilo que é próprio da música dionisíaca e, portanto, da música em geral, isto é, "a comovedora violência do som, torrente unitária da melodia e o mundo absolutamente incomparável da harmonia. 
No ditirambo dionisíaco o homem é incitado à máxima intensificação de todas as suas capacidades simbólicas.” (NIETZSCHE, 1992, p. 35). A música dionisíaca, comovedora e violenta, não é regular e previsível como a de Apolo, mas traz a novidade que assombra os que estão acostumados aos ritmos simétricos, serenos e equilibrados. Falando dos festivais gregos em homenagem a Dionísio, Nietzsche nos diz que "o cântico e a mímica desses entusiastas de tão dúplice disposição eram, para o mundo Greco homérico, algo de novo e inaudito: a música dionisíaca, em particular, excitava nele espantos e pavores." (NIETZSCHE, 1992, p. 34). Música dionisíaca era acompanhada da dança e de êxtase e "com que assombro devia mirá-lo o grego apolíneo” (NIETZSCHE, 1992, p. 35).

Em Humano, demasiado bumano, Nietzsche fala de uma alegria advinda da apreciação da simetria e do que é regularmente ordenado. "Já de espécie mais refinada é aquela alegria que surge à vista de tudo o que é regular e simétrico, em linhas, pontos, ritmos, pois por certa semelhança é despertado o sentimento por tudo o que é ordenado e regular na vida, exclusivamente ao qual tem de agradecer todo bem-estar: no culto do simétrico se venera, portanto, inconscientemente, a regra e a simetria como fonte da felicidade fruída até agora; a alegria é uma espécie de ação de graças." (NIETZsChe, 1983, p. 133). A música apolínea, sendo uma arte simétrica e regular com ritmos ordenados, causa em nós uma espécie de alegria serena que leva ao bem-estar. Entretanto, o prolongamento indefinido deste prazer advindo da regularidade dos ritmos pode saturar-se levando-nos ao sentimento de tédio. Somente a interrupção da simetria e da regularidade, pela inserção do inesperadamente novo que rompe com o antigo, causa em nos um prazer ainda mais refinado do que aquele efêmero prazer pela previsibilidade do regular. "Somente com uma certa saturação desta alegria mencionada por último surge o sentimento, ainda mais refinado, de que também na interrupção da simetria e da regularidade pode haver prazer" (Nietzsche, 1983, p. 133). Portanto, a interrupção da simetria e da regularidade causa em nós um sentimento mais refinado e prazeroso do que a continuidade previsível de um ritmo regular.

Nietzsche em $A$ origem da tragédia no espírito da música fala ainda da Canção Popular. "Mas o que é a canção popular em contraposição à poesia épica totalmente apolínea?” (NIETZSCHE, 1992, p.48). O rastro da união do apolíneo e do dionisíaco, sua prodigiosa propagação que se estende por todos os povos e cresce sempre com novos frutos. Apesar de tanto Dionísio como Apolo deixarem o seu rastro na canção popular, Nietzsche enfatiza que o substrato e o pressuposto da música do povo é o modelo dionisíaco. "Sim, deveria ser também historicamente comprovável que todo período produtivo 
no domínio da poesia popular também foi agitado ao máximo por correntes dionisíacas, que nos cumpre sempre encarar como o substrato e o pressuposto da canção popular”" (NIETZSCHE, 1992, p.48). Assim, preponderantemente a canção popular é uma experiência estética dionisíaca.

No pensamento estético nietzschiano a música tem um papel de destaque. Dionísio inspiraria a uma música inovadora que causa espanto e prazer estético no ouvinte habituado a previsibilidade do ritmo regular da música de Apolo e marcaria notadamente a música popular.

\section{Bergson e a comunicação do tempo}

Para o filósofo francês Henri Bergson o tempo é o estofo da realidade e sua principal característica é durar. Duração é o tempo real que dura e que passa continuamente transformando tudo, sendo ele próprio, mudança. Em termos ontológicos, para Bergson, não há a imobilidade; por trás do movimento há somente movimento, ou seja, por trás das coisas que mudam há uma essência que é ela própria, movimento, também. Devemos estar atentos a radicalidade da visão bergsoniana de realidade, para a qual não há imobilidade nem na superfície nem na essência. Neste mesmo sentido, não há a coisa que muda, há somente a mudança, porque "a coisa", toda ela, é movimento. Deriva daí o significado sutil, da palavra movente que, muito mais do que ser a qualidade daquilo que se move ou está em movimento, significa aquilo que é movimento; algo movente é aquilo que, em sua essência e totalidade, é movimento. O pensamento bergsoniano é inovador na tradição porque pensa uma essência que não é aquilo que permanece, mas é aquilo que muda constantemente. Bergson chama a esse movimento essencial da realidade de duração, que somente nos é dado a conhecer pela intuição.

Mas, não é assim que percebemos a realidade. Presos aos hábitos da inteligência visando nossa ação no mundo, percebemos a realidade como estática e passível de ser fragmentada em partes que facilitam nosso agir no mundo. Temos, assim, uma concepção espacial da realidade que olha o mundo do ponto de vista da extensão. A esta visão espacial da realidade, escapa o tempo real que flui incessantemente em seu contínuo movimento, porque pensa o tempo nos moldes do espaço e, assim, concebe um tempo ilusório: o tempo espacializado, originado da confusão que inadvertidamente se faz entre tempo e espaço. Dessa percepção equivocada, que não capta a essência temporal da realidade, surgem as dificuldades da linguagem para expressar o tempo. 
Agostinho nos diz nas Confissões: "O que é, por conseguinte, o tempo? Se ninguém mo perguntar, eu sei; se o quiser explicar a quem me fizer à pergunta, já não sei” (1983, p. 209) . Agostinho alerta para as dificuldades de expressão do tempo: podemos saber o que é o tempo, embora tenhamos dificuldades de dizer o que ele é. A comunicação do tempo é problemática do ponto de vista da filosofia bergsoniana.

O problema da comunicação da intuição da duração - duração entendida como o movimento essencial da realidade movente, ou dito de outro modo, duração entendida como o tempo criador de novas formas, nos remete ao conhecimento que por sua vez funda-se numa ontologia. Para Bergson (1971) a realidade é ontologicamente movente e sua essência é a duração. Duração é a essencial mudança incessante e contínua da realidade que, por sua vez, também é movente e indivisível. Duração é tempo, contudo, não é o tempo do senso comum ou da ciência, mas é um tempo criador da própria realidade; tempo que nos habita e nos constituí, tornando-nos criadores também.

Contextualizando a problemática, vemos que a metafísica tradicional sempre pretendeu conhecer a realidade tal como é em sua essência e para comunicar esse conhecimento, em um discurso filosófico, utilizou-se de conceitos. Entretanto, a linguagem conceitual mostra-se incapaz de expressar a essência dessa realidade movente e temporal. Isto porque o conceito, proveniente da cristalização da significação simbólica, paralisa o movimento das coisas para poder expressá-la, consequentemente, o conceito, ao tentar expressar a realidade movente, retira dela o essencial, isto é, seu movimento de duração. Logo, a linguagem conceitual é incapaz de dizer a essência da realidade e, assim, ao invés de aliada da metafísica é empecilho.

Para a metafísica bergsoniana, a única forma de conhecimento capaz de nos dar a essência da realidade movente é a intuição, precisamente porque segue seus contornos móveis, aderindo precisamente a eles. Entretanto, essa intuição em sua pureza não pode ser expressa por meio de símbolos, conceitos ou palavras, pois todas essas representações simbólicas remetem a uma forma de expressão exterior e fixa, e a intuição, por sua vez, é sempre interior e móvel. Essa impossibilidade de expressar adequadamente aquilo que é captado pela intuição, por meio de conceitos, faz surgir um dos problemas mais instigantes da filosofia intuitiva, o problema da comunicação da intuição. Resumido da seguinte forma: se a intuição é conhecimento, então deve ser expressa em linguagem, todavia, a linguagem somente dispõe de símbolos e, particularmente, de conceitos para se expressar; os conceitos paralisam o fluxo movente da realidade e, assim, a deformam ao tentar defini-la; logo, 
resta a questão: como expressar filosoficamente a intuição do movimento temporal incessante da realidade, sem paralisá-lo? A intuição do tempo, em sua pureza original, pode ser comunicada ao outro? E mais ainda, estaria a linguagem fadada a não dar conta de dizer o ser?

Posto o problema, Bergson aponta para uma possível saída sugerindo como caminho a utilização de imagens e metáforas para exprimir a intuição do tempo. Isto porque a metáfora não se fixa em um significado único, mas transmigra-se por várias significações, acompanhando as oscilações do real. Não é à toa que Bergson procura escrever de forma clara, fluida e dinâmica, como um rio fluente e límpido numa trajetória segura para quem nela adentra e, também, procura utilizar-se de muitas imagens, metáforas e analogias que muito mais sugerem que definem, pois a realidade que ele pretende comunicar é movente e fugaz, e presta-se muito mais à sugestão do que à definição.

Bergson indica o paradigma da arte para construir uma forma de expressão que dê conta de comunicar o tempo. Nesse sentido, a música, a poesia e a literatura, com sua abundância de imagens e metáforas, seriam formas privilegiadas de comunicação do tempo.

\section{Foucault e o discurso}

Foucault destaca o papel do discurso no conhecimento humano. $\mathrm{O}$ discurso é uma série de procedimentos por meio dos quais de estabelecem linhas divisórias entre o admitido e o não admitido. O discurso admitido pela sociedade indica sanidade, verdade e razão. Já os discursos não admitidos são excluídos pela sociedade e indicam loucura, falsidade e sexualidade. A importância dessa análise para a comunicação está na aplicação as questões da liberdade de imprensa e liberdade de expressão e de opinião. A existência de discursos não admitidos indica a existência de censura e, de certo modo, restringe a liberdade de expressão e de opinião garantida como direito fundamental do cidadão.

Outra contribuição de Foucault para a área de comunicação está na contextualização epistemológica do discurso. Para Michel Foucault, o discurso é “o que se diz". Todo discurso está associado à linguagem, mas não está restrito aos atos linguísticos, porque o discurso é uma ordem em virtude da qual se circunscrevem os campos da experiência e do saber possível, definindo-se "o modo de ser dos objetos" que aparecem nesse campo. Assim, o discurso está correlacionado a episteme, isto é, o paradigma epistemológico de compreensão e organização da realidade. A história comportou várias 
epistemes diferentes, como afirma Foucault (2002) em As palavras e as coisas: similitude, medida e organismo.

O Século XVI é marcado pelo paradigma da similitude. Nessa episteme, o mundo é explicado por meio de parentescos, afinidades, semelhanças e analogias. Exemplos de discursos: conchas, cervos e homens; animal e vegetal; o homem e a Terra. No século XVII o paradigma é o da medida e da ordem, a representação. Para esta episteme, a semelhança é uma ilusão, a analogia do paradigma anterior é substituído pela análise. Tudo é reduzido a elementos simples, grandezas que podem ser medidas e ordenadas segundo graus. Surge então, o Racionalismo, o mecanicismo e o paradigma matemático de explicação do universo. O Século XIX rompe co o passado e assume o paradigma da História e tem como modelo de explicação do mundo o organismo. O espaço geral do saber é feito de organizações, isto é, relações entre elementos, cujo conjunto assegura uma função. A História impõe suas leis à análise da realidade.

\section{Hannah Arendt e a visibilidade política}

Para Hannah Arendt (1906-1975), pensadora política alemã e autora de "A condição bumana", o homem se revela ao mundo no discurso e na ação. Sem a fala e sem o ato o homem não tem visibilidade no mundo. Quando fala e quando age o homem é capaz de comunicar a si próprio, e não apenas comunicar alguma coisa, porque nesse processo ele revela o seu próprio ser. "A ação e o discurso são os modos pelos quais os seres humanos se manifestam uns aos outros, não como meros objetos físicos, mas como homens" (ARENDT, 1991, p.189). Ação e discurso são essenciais para o homem, fazem parte de nossa própria condição humana, revelam a nossa humanidade. Portanto, a visibilidade, o aparecer ao outro é algo da própria condição humana.

Para destacar a importância fundamental do outro para a identificação do sujeito, Maria Rita Kehl recorre à psicanálise e nos diz que "eu sou” porque o Outro me vê. "O Outro é testemunha da visibilidade do sujeito, portanto de sua existência presentificada em uma imagem" (KEHL, 2004, p.149). Sem o outro que me veja, eu não me reconheço como sendo.

Nenhuma atividade humana precisa tanto do discurso quanto a ação. A ação necessita da palavra para ter visibilidade. "A ação que ele inicia é humanamente revelada através de palavras, e, embora o ato possa ser percebido em sua manifestação física bruta, sem acompanhamento verbal, 
só se torna relevante através da palavra falada na qual o autor se identifica, anuncia o que fez, faz e pretende fazer" (ARENDT, 1991, p.191). Se na ação o homem se revela e se mostra ao outro, não há ação sem visibilidade, porque não há ação sem o outro. Assim, a ação, que implica na presença do outro e da sociedade, vem acompanhada do discurso da fala que comunica a ação ao outro.

Para Kehl, o Outro como testemunha da visibilidade do sujeito, é uma instância pública simbólica que garante ao sujeito sua visibilidade, afinal somente há o aparecer se houver aquele que vê, dito de outro modo, se não houver o outro não há a visibilidade. A presença do outro é fundamental porque constitui uma instância de poder que confere ao sujeito seu ser no mundo. "Existir é, antes de tudo, apresentar a própria imagem para o Outro. O que equivale a dizer, para um adulto que já tenha ultrapassado as fronteiras dos complexos familiares, que existir é apresentar a própria imagem no espaço público. É no espaço público que o sujeito atesta que sua existência faz alguma diferença” (KEHL, 2004, p.150).

Para Hannah Arendt, tomando como modelo a Antiguidade grega, o que garante o ser para o sujeito, não é o pensamento, mas sua visibilidade. "Não é o pensamento que garante a singularidade do ser; isto é o que nos ensina a filósofa Hannah Arendt, baseada em seu conhecimento da Antiguidade clássica. O que garante o ser, para um sujeito, é sua visibilidade para outro sujeito" (KEHL, 2004, p.148). A polis grega não é a cidade-estado física, mas a organização da comunidade resultante do agir e do falar em conjunto. Seu espaço é o espaço da convivência e das relações comuns. Mais ainda, esse espaço é um espaço de aparência; "espaço no qual eu apareço aos outros e os outros a mim; onde os homens assumem uma aparência explícita, ao invés de se contentar em existir meramente como coisas vivas e inanimadas" (ARENDT, 1991, p.211). Assim, o espaço político, onde se tecem os acordos e se estabelecem as linhas que sustentam a vida de uma sociedade, é necessariamente o espaço do aparecer ao outro por meio da ação e do discurso.

A ação e o discurso são circundados pela teia de atos e palavras de outros homens. A vida sem discurso e sem ação é literalmente uma vida morta para o mundo, deixa de ser vida humana já que não é mais vivida entre os homens. Para agir e para falar o homem precisa estar entre os homens, assim, a ação e o discurso somente efetivam-se na vida social e política. Para Hannah Arendt, "os homens agem e falam em conjunto, que é a condição de todas as formas de organização política” (ARENDT, 1991, p.214). Poder e sociabilidade são intrínsecos. "O único fator material indispensável para 
a geração do poder é a convivência entre os homens" (ARENDT, 1991, p.213). Os homens só detêm o poder quando vivem próximos. Aquele que se isola renuncia ao poder e se torna impotente. O que garante o poder é o acordo, até mesmo frágil e temporário, de muitas vontades e intenções. Trata-se do estado democrático. A tirania, ao contrário é o exercício do poder no isolamento da força. Na tirania o governante tirano se isolados súditos e contradiz a condição humana essencial da convivência plural. A tirania, isolada e não visível, não efetiva a ação e o discurso, a força lhe basta. A ação jamais é possível no isolamento, estar isolado é estar privado da capacidade de agir.

Conceitos como espaço público e a visibilidade do sujeito na ação política, são mais facilmente detectados nas democracias, sobretudo, na ateniense que a originou. Para Hannah Arendt, a ação e o discurso conferiram à política uma dignidade que ainda hoje não desapareceu completamente.

Para Hannah Arendt, "O espaço da aparência passa a existir sempre que os homens se reúnem na modalidade do discurso e da ação e, portanto, precede toda e qualquer constituição formal da esfera pública e as várias formas de governo, isto é, as várias formas possíveis de organização da esfera pública”. (ARENDT, 1991, p.212). A ação e o discurso garantem a esfera pública. As comunidades políticas são baseadas no poder e o poder só é efetivado quando as palavras não são vazias e empregadas para velar intenções e os atos não são usados para violar e destruir, mas são usados para criar relações e novas realidades. O poder mantém a esfera pública, isto é, o espaço da aparência entre homens que agem e falam. Assim, a visibilidade é inerente ao processo político.

Para Hannh Arendt, agir implica em trazer ao mundo o novo. "Agir, no sentido mais geral do termo, significa tomar iniciativa, iniciar [... É da natureza do início que se comece algo novo, algo que não pode ser previsto a partir de coisa algum a que tenha ocorrido antes" (ARENDT, 1991, p.190). A imprevisibilidade é inerente a todo início e, portanto, a toda ação. Se a ação fosse totalmente pré-determinada deixaria de ser ação humana. O robô, o autômato, não age, porque é determinado e agir implica em liberdade e escolha. A ação verdadeira é a ação livre que emana do próprio sujeito que age, o agente. Por causa de sua inerente imprevisibilidade, a ação é criadora, viola os limites, transpõe as fronteiras e inova.

A novidade resultante da ação humana é responsabilidade do agente da ação. O novo sempre acontece contrariando as leis da estatística e da probabilidade, porque é resultado da liberdade humana. "O fato de que o 
homem é capaz de agir significa que se pode esperar dele o inesperado, que ele é capaz de realizar o infinitamente provável” (ARENDT, 1991, p.191). É porque o homem age que ele traz ao mundo a novidade, ele inova. O mero fazer automático, a repetição ou a atividade totalmente pré-determinada não podem ser consideradas, verdadeiramente, como ações. A ação implica em liberdade, em escolha. E é nesse momento que surge a responsabilidade.

É da natureza da ação revelar seu agente, consequentemente, torna visível aquele que responde pela ação. $\mathrm{Na}$ ação e no discurso, os homens mostram quem são, revelam ativamente suas identidades pessoais e singulares, e assim, apresentam-se ao mundo humano. Sem a revelação do agente do ato, a ação perde seu caráter específico e torna-se um feito como outro qualquer, isso porque quando age e quando fala o homem revela o seu próprio ser e, assim, torna publico e visível ao outro o responsável pelo discurso e pela ação.

No espaço público, onde se estabelecem relações de poder, as imagens importantes são as imagens de homens em ação. A visibilidade dos homens políticos depende de sua ação política. "Aqui é necessário inserir um vetor ético: a visibilidade no espaço público implica que os sujeitos se responsabilizem pelos efeitos de seus atos na vida da polis" (Kehl, 2004, p.150). A ação política, indissociável da fala política, revela sempre seu agente, que assim, ganha existência pública a partir dela, e consequentemente, responsabilidade por seus atos na esfera política.

\section{Considerações Finais}

O diálogo entre a Filosofia e a Comunicação propicia uma reflexão epistemológica sobre temas e questões cruciais que envolvem o fenômeno da comunicação humana e social.

A comunicação como fenômeno é tão antiga quanto à própria humanidade e foi tema de discussão filosófica desde os primórdios do pensamento ocidental. Mas somente no século XX, a Comunicação se instituiu como área própria do conhecimento e pode aproveitar o legado da filosofia para consolidar-se como objeto específico do conhecimento humano. Nesse sentido, este artigo buscou indicar dentro da história da filosofia ocidental alguns momentos em que diversos filósofos trataram de temas próximos da comunicação como cinema, música, tempo, discurso e visibilidade e, assim, sugerir um aporte para uma reflexão interdisciplinar sobre a própria comunicação. 


\section{Referências}

AGOSTINHO. Confissões. São Paulo: Victor Civita, 1983.

ARENDT, Hannah. A condição humana. Rio de Janeiro: Forense Universitária, 1991.

ARISTÓTELES. Política. São Paulo: Martins Fontes, 1998.

BERGSON, H. A evolução criadora. Rio de Janeiro: Opera Mundi, 1971.

BERGSON, H. Cartas, conferências e outros escritos. São Paulo: Abril Cultural, 1984.

BUCCI, Eugênio e KEHL, Maria Rita. Videologias. São Paulo: Boitempo, 2004.

CUNHA, José Auri. Filosofia. São Paulo: Ática, 1992.

FOUCAULT, Michel. As palavras e as coisas. São Paulo: Martins fontes, 2002.

NIETZSCHE. Humano, demasiado humano. São Paulo: Abril cultural, 1983.

NIETZSCHE. O Nascimento da Tragédia. São Paulo: Companhia das Letras, 1992.

MOUTSOPOULOS, E. La critique du platonisme chez Bergson. Athènes: Grigoris, 1980.

PLATÃO. Diálogos. São Paulo: Victor Civita, 1983. 